\title{
Bringing Trauma to School: The Educational Experience of Three Youths
}

\author{
Jennifer Dods \\ Queen's University
}

\begin{abstract}
Experiencing a traumatic event can impact students' well-being and jeopardize their academic achievement and social-emotional health. A quarter of all students will experience a traumatic life event before they graduate from high school (Costello, Erkanli, Fairbank, \& Angold, 2002), necessitating an understanding of how trauma affects students in the school context. This paper brings the perspectives of three youths to the forefront and explores their educational experiences and their perception of the role schools play in supporting students who bring trauma to school. A qualitative case study design and personal interviews with the youth led to the findings reported here. The presentation and management of the trauma and resulting stress differed among participants, and overall school experiences ranged from very negative to very positive. Participants were more unified in their perceptions of what they wanted from schools and the role that school could play. Themes across cases emphasized the importance of teacher driven, supportive, caring relationships, and the need for schools to focus on student well-being as well as academic functioning. The protective nature of school connectedness, in increasing engagement and decreasing at-risk behaviours and emotional distress (Blum, 2005; Bond et al., 2007; Klem \& Connell, 2004; McNeeley, Nonnemaker, \& Blum, 2002), holds promise for students with traumatic stress.
\end{abstract}

Each morning as high school doors open, students enter bringing with them a diverse array of both past and current life experiences that shape who they are and how they learn. Some students arrive at school feeling safe and settled, and focused on the tasks at hand. For other youth, the realities of living through traumatic life events create barriers 
that impede their learning and functioning in the classroom and that take a toll on their overall well-being. The complexity of this intersection between life and learning is an ever-present challenge facing teachers as they seek to engage students in high school classrooms. This paper describes the educational experiences of Nick, Natasha, and Sarah, three youth who had experienced traumatic events in their lives and were willing to share their perspectives on the role that schools and teachers can play in supporting well-being and academic success.

Teachers are often unaware of the occurrence or effects of traumatic events in the lives of their students, yet they deal everyday with the challenges these bring to their classroom (Dwyer, Nicholson, Battistutta, \& Oldenburg, 2005). Experiencing trauma can alter a young person's sense of security and ability to make sense of the world around them, impacting all areas of a youth's life, including how they act and react, how they feel and think, and how they relate to others (Steele, 2002). The response of educators to both overt and subtle signs of trauma-related distress contributes to the overall well-being and academic success of students.

Current perspectives in the research provide a clinical picture of the typical behavioural and emotional manifestations of that distress and the likely impact on academic and social outcomes. What is missing across the research is the perspective of the youths themselves, putting into context what the clinical and scientific evidence means to the educational experience of students who have lived through traumatic life events. Understanding the personal impact of traumatic experiences can lead to a greater awareness of and sensitivity to how student behaviour is perceived and supported in the classroom (Liamputtong \& Ezzy, 2005). The negative social, academic, psychological, and behavioural consequences associated with trauma have been well documented. Deepening our understanding of the protective role that schools and teachers can play for these students is critical to mitigating negative effects and improving student outcomes. Despite the reality that the majority of students dealing with traumatic stress will spend their day in a classroom, there is a paucity of literature on this topic in the field of education. Schools are uniquely situated to support students, necessitating an increased awareness of trauma- and traumatic-stress-related experiences in order to foster school environments that are responsive to these youths. To address this gap this paper provides the qualitative viewpoint of three young adults, situating the research in the school context.

\section{Theoretical Perspective}

To frame this study, a brief overview is provided of trauma and traumatic stress and of current evidence of the impact of trauma on learning. Trauma theory describes the needs created by traumatic events and, along with research on school connectedness, offers a framework for addressing challenges resulting from the intersection of trauma and learning in the school context.

\section{Trauma and Traumatic Stress}

Once thought to be a rare event experienced primarily by military veterans returning from war, traumatic stress is now known to be pervasive, affecting people of all ages and 
in all walks of life. Traumatic injuries, assaults, abuse, natural disasters, and sudden loss are examples of other experiences that may be experienced as traumatic and lead to trauma-related distress. Trauma is a subjective event defined as an actual or perceived threat to one's physical integrity causing extreme stress that overwhelms the body and brain's ability to cope (Terr, 1991). It is accompanied by feelings of intense fear, horror, terror, and helplessness and can lead to post-traumatic stress, characterized by intrusive thoughts, avoidance behaviour, hyperarousal, and /or changes in mood and cognition (Terr, 1991). In some students, trauma-related distress is evident in overt externalized or internalized behaviour; however, for others the signs of distress are far more subtle. In the absence of disclosure it is unlikely that trauma would be considered to be at the root of emotional and behavioural needs seen in the classroom or to be the reason for more subtle shifts in behaviour, appearance, and demeanour. As clinical signs are often not easily identifiable or even present, distress related changes in behaviour, personality, attention and memory, deteriorating grades, peer relationships, compliance, and attendance may be falsely attributed to factors assumed to be within the student's control or to normal teenage angst.

The majority of studies examining the prevalence of trauma and traumatic stress have focused on populations of at-risk youth. In specific at-risk populations, more than $90 \%$ of youth involved with juvenile justice (Arroyo, 2001), $75 \%$ of youth accessing substance abuse support (Funk, McDermeit, Godley, \& Adams, 2003), and 93\% of adolescents receiving psychiatric services (Lipschitz, Winegar, Hartnick, Foote, \& Southwick, 1999) reported histories of trauma. In poor urban neighbourhoods, the experience of trauma was almost universal (Yule, 2001. One of the few studies of broader populations found $25 \%$ of all youth surveyed and $68 \%$ of those who self-reported emotional and behavioural symptoms had experienced one or more traumatic events (Copeland, Keeler, Angold, \& Costello, 2007; Costello et al., 2002). While fewer studies have looked at prevalence in middle-class youth, an examination of middle class adults in the Adverse Childhood Events study revealed $60 \%$ of middle-aged adults recalled a traumatic event that happened during their childhood or adolescence (Edwards et al., 2005). While the majority of those who experience trauma will not meet criteria for a diagnosis of post-traumatic stress disorder (PTSD), many will experience post-traumatic stress and the subsequent development of depression, anxiety, disruptive behaviours, delinquency, and/or substance abuse (Edwards, Anda, Felitti, \& Dube, 2004).

\section{Impact on Learning and Well-Being}

The classroom environment itself, a crowded and confined space with a large number of people, can create challenges for someone who is experiencing the emotional and behavioural reactivity of traumatic stress. Classes are structured and scheduled and are often busy and loud, making it difficult for students to regain a sense of calm and control and to decrease arousal levels. A youth's behaviour at this point may be instinctively motivated by his/her stress arousal level, and actions taken are done so with the intent of minimizing the perceived threat and restoring a sense of control (Beers \& De Bellis, 2002). Often this is referred to as the fight, flight, or freeze reaction. To the observer the student may appear distracted or to be having difficulty following directions or staying on task. Behaviourally students may seem oppositional or unpredictable, 
overreacting to seemingly minor provocations. Vivid, intrusive memories of the traumatic event may lead students to utilize avoidance strategies evidenced by dissociating (mental avoidance) or running from people, places, or situations that are associated with the perceived threat (physical avoidance).

Research on the impact of trauma on learning finds challenges for students in the areas of behaviour, attention, memory, motivation, deteriorating grades, peer relationships, compliance, and attendance (Cook et al., 2005; De Bellis, 2005; KendallTackett \& Eckenrode, 1997; Perry, 2002; Ratner et al., 2006; Rowe \& Eckenrode, 1999; Yasik Saigh, Oberfield, \& Halamandaris, 2007). These distress-related changes may be falsely attributed to factors assumed to be within the student's control, and can lead to misunderstandings and consequences that further exacerbate the student's distress and impairment, possibly contributing to disengagement and, ultimately, school failure.

The overrepresentation of youth with histories of trauma in special education is also telling. Sullivan and Knutson (2000) reported that almost a third of all children in special education and a full $50 \%$ of all children with an identified behaviour disorder had recorded histories of maltreatment. Ferguson et al. (2005) noted in their extensive review of early school-leavers in Canada that half of the disengaged students had emotional or behavioural disorders. Ultimately $50 \%$ of students identified with emotional or behavioural needs drop out of high school (Meichenbaum, 2006). Even in more resilient youth who went on to higher education, the effects of trauma remained. Only $35 \%$ of college students with two or more childhood experiences of abuse remained enrolled in college by their fourth year (Duncan, 2000). These longer-term outcomes are likely due in part to the relationship between trauma and risk for chronic anxiety disorders, major depressive disorder, substance use, suicidal ideation, educational underachievement, dysfunctional relationships, early parenthood, and poor physical health (Bardone et al.,1998; Edwards et al., 2004; Johnson, McGue, \& Iacono, 2006; Woodward \& Fergusson, 2005). In all instances a comorbid substance abuse problem leads to poorer outcomes in youth who have experienced trauma, with more than a third of youth abusing substances as a means to cope (Hall, Degenhardt, \& Teesson, 2009; Vida et al., 2009). Keeping students engaged at school can positively impact not only employment and income opportunities but also overall health and well-being.

\section{Constructivist Self-Development Theory}

Constructivist self-development theory (CSDT) postulates that all trauma is transformative, and it describes adaptations to trauma as an intertwined web of variables, creating unique experiences for each individual (McCann \& Pearlman, 1992; Saakvitne, Tennen, \& Affleck, 1998). The meaning of the traumatic event comes directly from the survivor's experience and construction of the event. Each individual's adaptation to a traumatic event involves identifying and addressing core areas that have been disrupted and working to reconstruct and renew these core areas of the self. McCann and Pearlman identified the disrupted areas as self-capacities (abilities that enhance self-regulation), ego resources (skills to manage the interpersonal world), psychological needs (security, trust, esteem, intimacy, and control), and frame of reference (including identity, world view, and spirituality). While trauma is transformative and initially disruptive, the authors 
contend that by focusing on well-being and rebuilding the areas impacted by the trauma, outcomes can be very positive and lead to personal growth and success. The theory positions RICH relationships as the driving force behind trauma recovery to restore the needs disrupted by the trauma, with the essential elements being RICH-respect, information, connection, and hope (Pearlman, 2013). Within the school setting, teachers can play a key role in supporting this recovery and in rebuilding these unmet needs. While not specific to trauma, school connectedness and, most importantly, studentteacher relationships, provide a framework to implement trauma-informed practices and RICH relationships in the school context.

\section{School Connectedness}

Little research has been undertaken on the relationship between trauma histories and school connectedness; however, the parallels in emotional, behavioural, and academic outcomes for other at-risk groups of students would suggest similar protection for students who have experienced trauma. Blum (2005) defined school connectedness as "an academic environment in which students believe that adults in the school care about their learning and about them as individuals" (p. 16). Various components have been examined as being part of this construct including school belonging, school climate, teacher support, student-teacher relationships, and student engagement (Blum, 2005; McNeeley, 2005). Students describe school connectedness from their perspective as feeling like they belong, liking school, believing teachers care about them and their learning, having friends at school, believing that discipline is fair, and having opportunities to participate in extracurricular activities (Blum, 2005). Recent literature has suggested that students who report feeling connected to their school are less likely to use substances, exhibit emotional distress, demonstrate violent or disruptive behaviour, experience suicidal thoughts or make suicide attempts, skip school, become pregnant, or be involved in bullying or vandalism (Blum, 2005; Klem \& Connell, 2004; McNeeley, Nonnemaker, \& Blum, 2002; Saewyc, Wang, Chittenden, Murphy, \& The McCreary Centre Society, 2006). These same studies also found students were more likely to succeed academically and to graduate. In one of the few trauma-related studies, Saewyc et al. (2006) found that a sense of school connectedness was the primary protective factor-above and beyond individual, family, or peer factors - in British Columbia youth who had been abused or came from challenging home situations, .

Among the components of school connectedness examined by McNeeley (2005), teacher relationship was found to be the aspect of school connectedness that best predicted decreased at-risk behaviour (McNeeley, 2005). A group of at-risk students (Ozer, Wolf, \& Kong, 2008) in an urban school identified that, for them, the small things such as knowing their name and noticing absences were evidence of a teacher caring. The authors concluded that "overall students played a passive role in their interactions with teachers about problems other than academic," yet also "expressed gratitude for teachers who made even small overtures to find out about their lives outside the classroom" (Ozer et al., 2008, p. 454). Teachers also identified caring as being of great value in building relationships with at-risk students, and reported their belief that for some students caring was as important as the academic component of education (Calabrese, Hummel, \& San Martin, 2007). Teachers have identified mental health issues as the greatest health need 
of students and the least serviced (Mansour, Kotagal, DeWitt, Rose, \& Sherman, 2002; Walter, Gouze, \& Lim, 2006). Teachers reported very low levels of comfort with identifying trauma and responding to traumatic stress (Walter et al., 2006), with a lack of education and training being the barrier to recognizing and accommodating traumarelated needs (Mansour et al., 2002; Walter et al., 2006). Efforts have been made in recent years to increase teacher awareness of the impact of trauma on students in the classroom through publications and professional development sessions (Cole \& Styron, 2006; Downey, 2007).

Given the reported positive benefits of school connectedness on the physical, emotional, and academic health of students, it appears to be a construct that could greatly benefit students who have lived through trauma. Developing school connectedness ultimately requires that both teachers and school administrators are able to provide high expectations coupled with support for learning, positive student-teacher relationships, and a physically and emotionally safe school environment (Hutchinson, 2009; Wilson \& Elliott, 2003).

\section{Method}

A qualitative case-study design (personal interviews) was used to derive meaning from the perspectives of those living the experience being studied, and to provide a glimpse into the life of someone else (Liamputtong \& Ezzy, 2005; Patton, 2002); in this case, the educational experience of three young adults in a small city in Ontario who had experienced trauma was studied. Qualitative interviewing assumes that the perspective of others is "meaningful, knowable and able to be made explicit" (Patton, 2002, p. 341), and the case-study design enhances appreciation of the "uniqueness and complexity of the case, its embeddedness and interaction with its contexts" (Stake, 1999, p. 16). This study looked at individual youth experiences within the context of high school. Given the sensitive nature of the topic, the personal interview was appropriate and was familiar to me as a psychiatric nurse.

\section{Participant Recruitment}

Postings were placed on popular online community sites (Kijiji and Facebook) for southeastern Ontario, and interested young adults responded by contacting an email address given. As trauma is a subjective experience, no boundaries were placed on what events could be perceived as traumatic events. The inclusion criterion was the experience of one or more traumatic events resulting in traumatic stress. Respondents were screened by asking them whether they had recently been in school, were willing to reflect on trauma experiences, and had stable mental health with supports available to them. These criteria were in place to ensure participants were able to articulate and show insight into their experiences in a meaningful and safe way. Those who met the criteria also were asked to complete the Trauma Symptom Inventory (TSI-A) scale (Briere, Elliott, Harris, \& Cotman, 1995) to distinguish between traumatic stress and other mental health issues (e.g., depression, anxiety) that may or may not have been trauma related. The recruitment process resulted in three young adults aged 19 to 21 who each reported experiencing multiple traumatic events over the course of their lives, with interpersonal trauma (e.g., 
abuse, assault) being a shared characteristic. An interesting result of using online social media sites to recruit was access to middle-class youth who are not often represented in research on trauma. All three participants had been in the academic stream in high school, had made plans to pursue post-secondary education, and were all from two-parent homes.

\section{Data Collection and Analysis}

Data were collected over a six-week period through the completion of a standardized questionnaire and an in-depth, semi-structured interview with each of the three focal participants. The initial meetings to establish rapport took place in coffee shops, and the interviews took place in a location chosen by the participant (participant's home or a private meeting room in a public location).

The questionnaire used was the Trauma Symptom Inventory-alternate item scale (TSI-A; Briere, et al., 1995). The TSI-A is an 86-item scale that can be completed in 1530 minutes and has well-established psychometric properties (Briere, et al., 1995. This measure was chosen as it is non-diagnostic, is not specific to any particular trauma, and does not ask about the traumatic event, instead focusing on symptom categories. The TSI-A questionnaires were reviewed for both validity and clinical scale scores. Elevated scores on anxious arousal, intrusive experiences, defensive avoidance, and dissociation are indicative of post-traumatic stress. This information was used to ensure that the distress that students reported having experienced in school was trauma-related stress.

The interview tool was developed by the researcher and was designed using a combination of introductory and background questions to establish rapport, and openended questions meant to allow the participant to share their opinions, thoughts, feelings, behaviours, and values related to the classroom experience (Patton, 2002). Questions related to the impact of the stress resulting from the traumatic event on functioning within the classroom, rather than to the traumatic experience itself. Knowing the details of the trauma was not essential to the research, as traumatic stress responses are determined by how a traumatic event is experienced, rather than by the specific nature of the trauma itself. Participants were told they could describe their trauma if they wished but were not asked to do so due to the sensitive nature of trauma disclosure and the time-limited, nontherapeutic relationship with the interviewer. Feedback on the interview tool was sought and provided by three experts in the field, and was used to modify questions. The interview was semi-structured and asked participants to describe how their traumatic stress presented itself in their lives, the impact it had on them socially and academically, their perceptions of support in the school context, and the role of teachers in supporting students.

The researcher met with two participants twice in the collection of information, and the third participant once. During these meetings each youth reviewed the letter of information, signed letters of consent, completed the questionnaire and participated in one 50-60 minute interview. In all cases the interviewer spoke informally with the participants following the interview for varying periods of time to diffuse any emotion and to end the conversation on a casual note. The interviewer touched base with each participant within 48 hours following the interviews, and all participants reported that the interview had been a positive experience. 
Observation notes were made both during and after the interviews and contributed to the iterative analysis. Two of the three participants later reviewed the transcripts for accuracy. Interviews were transcribed and analyzed individually to ascribe meaning to each unique case. Each transcript was read several times and codes were generated using both an inductive and a deductive approach. Codes were then categorized and used to develop themes. Following the individual analysis of each case, a cross-case analysis was conducted to allow for examination of the data from a perspective that cannot be achieved through individual case analysis. For the cross-case analysis, the codes of the three transcripts were reorganized into new categories, and themes were derived from these categories to identify patterns and commonalities in the experiences of the three young adults.

\section{Participant Profiles}

All three participants reported living in a middle-class home with married parents who had post-secondary education and professional careers.

Natasha was a 19-year-old young woman who experienced conflict in her home and multiple interpersonal traumatic events in her community between the ages of 14 and 16, leading to her life spiralling out of control. As a result she spent a year moving among inpatient psychiatry, juvenile detention, and a group home, before returning to her home and high school for her Grade 11 year. While her life had stabilized, she found the school environment to be challenging and unsupportive, and she dropped out near the end of Grade 11. Natasha moved away from home and was working two part-time jobs and caring for her young son at the time of the study. She had no interest in returning to school and was making plans to start a small business that she could run from home.

The second participant, Sarah, aged 21, had experienced interpersonal trauma in her home throughout her childhood and adolescence. Sarah excelled academically and was in the gifted program throughout her school years. She received a full scholarship to university and moved away immediately upon graduating; however, she struggled to complete her first semester due to traumatic stress, and left school to seek therapy. When we met, Sarah was working in retail and had plans to return and complete her degree.

Nick was a 21-year-old man whose trauma began at the age of six with the murder of a sibling. His family unravelled, and he described further trauma as a "solid decade of different shitty things" occurring both at home and in the community. Nick graduated from high school and spent one semester in a college science program before leaving his hometown and school to join the military. He intended to remain in the army as he believed it was a good fit for him. Nick had continued to struggle with post-traumatic stress but had not sought therapy, preferring to deal with it by having a positive attitude and by focusing on his job and his young son.

\section{Findings}

Participants provided in-depth descriptions of their educational experiences and of the impact of the trauma on their lives while in high school. First I highlight the unique experience of the three participants before looking at themes across the three cases. 


\section{Natasha}

In one word Natasha's experience at school would be "overwhelmed." She talked about the sensory overload that she felt upon her return to school and described what was going on in her head as "a hundred people in a very small room". Intrusive memories of the trauma and stress responses were triggered by sights and smells in the school hallways, leaving her "dizzy and weak ... sick to my stomach almost." Throughout the interview she spoke of being "cloudy upstairs" and of going through the day in her own world to the point that "a lot of things seemed surreal." While in class Natasha managed her "zero concentration" and "jittery and restless" feelings by doodling and drawing in an effort to distract herself. While this had a calming effect, her lack of focus on the academic task led to falling behind in class, further overwhelming her.

Natasha's efforts to cope with her distress were primarily avoidance-related, as she would leave class_-or, as she put it, "physically dismiss myself"-when overwhelmed and would often not return, stating that "something as simple as being in class was just too hard." Often leaving class was driven by a need to find a place where she felt safe and to avoid becoming tearful in front of others. The place where Natasha felt safest was the girls' bathroom, which was to her "every girl's sanctuary"; and she recounted spending considerable time sitting on the counter in the bathroom. Natasha was able to find sources of support within the school setting in two staff members, a school nurse and Bill, a member of the support staff, who both provided a listening ear and safe place to go when she couldn't cope. She described how Bill “... would see me and be like, 'Why do you look so sad?' and when I would talk to him I'd feel like someone genuinely cared." When struggling in class Natasha was able to leave and seek safety and comfort from these sources; however, the fact that these two individuals were removed from the classroom setting meant that their support did not transfer to academic engagement or feeling safe in class.

Natasha's school was aware of some of the trauma that had occurred in her life, and her return was a planned event that included consultation with the principal and her parents, and reassurance that support would be provided. Initially Natasha perceived teachers as "more understanding," but as she continued to struggle over the course of the year, she felt that their patience wore thin and that they felt she was "faking" and "didn't believe me" and "didn't really care." When one teacher made a sarcastic remark, saying, "Oh, Natasha, you chose to join us today." Natasha experienced this as humiliating, and it made her feel that "you just don't want to go back after that." Natasha's behaviour escalated due to her perception that no one was listening. Drug use and involvement in high-risk activities were seen by Natasha as behavioural efforts to externalize her distress in the hopes it might be noticed. A decreased sense of self-worth and feeling of guilt also led to self-harming behaviour and suicidal ideation, neither of which she felt were understood by others. Ultimately she lost many of her higher achieving friends and sought out peers engaged in similar high-risk behaviours.

Natasha's classroom experience was mixed. She described often coming to class unprepared and struggling to complete assignments, noting that teachers would not understand why. To her, the effort she was putting forward in "just remembering what room it is in and going" and in handing in partial assignments went unnoticed. Attempts 
to explain to teachers that "it is hard to do something like school that's logic when you don't have any logic left" went unheard. Despite her frustration with feeling unsupported, Natasha was quick to acknowledge her English teacher who was "really, really nice to me." While they didn't discuss the underlying issues, Natasha felt that this teacher could tell when she was having a difficult time in class and would quietly give her permission at times to leave the classroom. As the year progressed, Natasha's sense of disengagement grew as she struggled to keep up and perceived her work as "never being good enough." Ultimately she left school: "I tried but I had no connection with anyone that was there, and I didn't care at that point ... I felt like none of it really mattered to anyone so I was wondering why I was feeling this way if it didn't really matter."

From her experience, Natasha offered two pieces of advice for teachers. The first was to "never bother people in front of the whole class-I think that's the worst." Regardless of teacher intent, Natasha experienced significant humiliation when confronted publicly and singled out, as this further contributed to her anxiety and distress, and to her decision to drop out of school. Her solution was for teachers to address any issues privately and to offer help at the same time, stating what she would have wanted to hear was, "Look, Natasha, we got your paper back and you missed the point, but it's all right - come with me at lunch or after class and I'll help you out."

The second piece of advice that Natasha had was the need for flexibility and understanding regarding her lessened ability to meet expectations. Natasha felt that teachers could demonstrate this understanding by being flexible with students leaving class if they know they are struggling, and by not making a big deal "if I forget to bring the right book to class." She reflected on how much longer her work took her due to difficulties focusing and concentrating and on how she could have benefited from extra time to complete projects. She also relayed struggling to understand abstract ideas and questions due to her anxiety, and recalled working on assignments for hours and hours only to be told she had done it wrong. Natasha said that one of the few things that gave her hope was when she received a good grade and advised teachers to "be more lenient when someone has an issue" in order to "give the person that little bit of encouragement that it takes to get that person back on track."

Summary. Natasha's case contains many of the classic representations of a reaction to trauma. She discussed the presence of specific traumatic stress symptoms and both externalized and internalized behaviours she used in an effort to manage the symptoms and distress. Her efforts to cope and to seek support were unsuccessful in the school context. A lack of agency and an externalized locus of control made it difficult for her to negotiate the supports she needed to manage the workload and school environment. Near the end of the school year, her feelings of disconnection and disengagement stemming from the belief that no one cared, including herself, resulted in her decision to leave school. Once out of the school environment, Natasha was able to regain a sense of control and to take charge of her life and mental health. 


\section{Sarah}

Sarah's experience at school was in many ways the opposite of Natasha's. Sarah began the interview by describing her lifelong love of school and by expressing her appreciation that in the absence of nurturing support or pro-social modeling at home, school was the only place where those needs were met. High school played another vital role for Sarah, as graduation was her "ticket out" of her home and an escape from the trauma. She was determined that nothing would keep her from succeeding and "the only thing on my mind was if I get out now, if I do well enough and get a scholarship ... I can get out and never have to come back." To accomplish this and to hide her embarrassment at her home life, Sarah described "being two different people" and "living a double life." She stated that as she walked out of her house each day she "literally put on a new face." This allowed Sarah to maintain a sense of normalcy at school, something that Sarah identifies as being "really important to me at the time." School was Sarah's safe place, a reprieve from the ongoing trauma at home; and she described school as the thing that "kept me going ... it's all I had."

Despite her best efforts to leave her trauma at home and her success in hiding it from others, Sarah reported that even at school "it [trauma] was always on my mind"; and the resulting anxiety would frequently surface. She recalled having panic attacks and walking out of class, waiting until they dissipated before returning. The effort required to control her emotions and maintain the secrecy of her double identity provoked further guilt and anxiety. To manage these feelings and her increasing depression, Sarah withdrew, stating, "I put myself inside myself, I was very, very closed off."

The main manifestations of Sarah's ongoing distress were lifestyle changes and resulting shifts in dress, peer group, and demeanour. She described how she returned to school for Grade 10 as a goth and switched from the "popular clique group to the outsiders," where she began smoking and using illicit drugs. No longer able to identify with her old friends, she found she could relate best to those on the fringes who also had issues. She later changed her style from goth to punk and the "rebellious" look. For Sarah these were extreme changes that were "a way of reflecting a lot of my anger" and "one way to show I had some issues without necessarily saying it." In her last year of high school Sarah left behind her previous styles, exploring Buddhism in an attempt to find "sanctuary." While Sarah's quiet demeanour and high academic achievement masked her distress, she spent much of high school trying unsuccessfully to give subtle cues that she was struggling and in need of support.

These indirect attempts to let others know she was struggling went unnoticed, leading to Sarah's feeling she was invisible at school. Sarah attributed her invisibility to her high academic achievement and the fact that "I wasn't a problem so they just kind of skimmed right over me." When dealing with her anxiety she could get up and walk out of class and "because I was a good student they just figured I'd gone to the bathroom ... no one really asked if I was okay or if anything was wrong." It was more mystifying to her that the change from a popular in-crowd student to being goth was also overlooked. To her these were extreme changes, and she reflects, "To this day I just can't understand it, how they didn't clue in," and "How could you not know there was something wrong?" 
She was incredulous that the combination of her lifestyle changes, walking out of class, and two out-of-character emotional outbursts did not raise red flags.

There were teachers in the school whom Sarah felt she could trust and to whom she would hypothetically have opened up, had one of them asked her what was wrong. She shared that she "really wanted to connect with more teachers," but saw herself as only one of many students with no access to individual time with teachers. Sarah felt one of the only opportunities to develop a trusting relationship with teachers was through involvement in extracurricular activities, but she wasn't allowed to participate. As she told her story, Sarah revealed that even if teachers had asked, she might not have disclosed the abuse at home out of fear teachers wouldn't really listen and would take action and "tell the police" or contact "children's services." To her these were extreme actions to be avoided as "I'm so close to leaving, I don't want them to screw it up for me." What she really wanted was for a teacher to reach out to her and demonstrate care.

Sarah's first piece of advice for educators was to provide instrumental support; she wanted schools to improve the accessibility and availability of resources. She stated, "I felt extremely alone. I really needed someone to tell me that I wasn't alone, that other kids were going through this ... I never found that." Acknowledging that many students will not approach teachers, Sarah suggested a variety of written materials should be readily available to students. Sarah further advocated for information on topics that most students might typically receive at home because, as she says, "I didn't learn a lot of the things that a regular person should learn," and that the only things she knew about coping and "socialization" were what she had learned in school.

She also emphasized the need for teachers to be attuned to student's behaviour and changes that extend beyond academics to the realms of social networks and lifestyles. Sarah's perception was that teachers "only focused on those who are struggling academically" and in doing so didn't pick up on her distress or that of others. The ability to pick up on covert signs of depression and distress was paramount to Sarah. She said that "... struggling socially to find yourself" and changes in her body language and being "completely shut off" were signs teachers could have picked up on. Sarah's emphasis on teacher awareness and responsiveness was based on her belief that if teachers noticed distress they might initiate a trusting relationship and support the student.

Summary. Sarah's description of her experience highlights a case of a student with high achievement yet with poor overall well-being and impaired functioning in nonacademic domains. While she spoke of experiencing many of the typical symptoms of traumatic stress, she put a great deal of effort into minimizing them at school in order to appear "normal." School was an anchor for Sarah; and excelling was of great importance, as "it was the only place I was good at anything," and it offered her a future. Similar to findings in the literature, for Sarah, school was the only place for contact with professionals who might be able to help her, and teachers were her only positive connections with adults. Her high achievement meant that teachers did not view her as a student "at risk," but her case emphasizes the importance of looking beyond academic achievement as the marker of success. Sarah saw herself as the master of her own future; and for that reason her choices were not necessarily in her best interest, but rather were choices that allowed her to achieve her immediate goal at the expense of her overall well-being. 


\section{Nick}

Nick's experience differed from those of Natasha and Sarah, with his level of school engagement falling between the two. Having lived with trauma from an early age, Nick's entire school life had been influenced by trauma and traumatic stress. From Grade 4 until Grade 11, his primary motivation for attending school was to hang out with peers and to avoid repercussions at home if he missed school. Reflecting on school, Nick says that he spent a lot of his time "daydreaming, ... trying to forget about things that had happened" and participating in high-risk activities because "the thrill of doing things I shouldn't have done really helped out with [forgetting]." By middle school Nick was using drugs on a daily basis and described himself as disengaged and as "just a bad kid." He recalls, "My teachers started saying, we know you are able to do the work, you are intelligent, we know you get it but you don't hand anything in."

In the school setting, Nick struggled to manage his highly reactive behaviour. He described that "when stuff was really bad at home, then I'd be on edge all the time- -having a constant readiness, always on guard for something." Aware that he overreacted at times, Nick described how "I'd just snap" and how he "would try everything to calm myself down." Nick preferred to walk away, and "if I was in a situation where I could leave, I would leave"; but "if I was in a school setting and I couldn't leave and ... I ever felt physically trapped, I would flip out and cause the most possible pain to that thing to get me out of that situation." Despite numerous physical altercations in high school, Nick recalled that the times he was in trouble were usually due to not paying attention and being off-task rather than for fighting. Nick reflected that this aspect of his traumatic stress did take away from his school success. "Always being on guard and worrying about things or always trying to forget about things. I really do think it took away from, maybe not being able to learn but from the concentration to go through the learning process." He added, "Being screwed up ... made [learning] very hard, I had a short attention span."

Nick also needed others to see him as strong and in control and did not want anyone to see his behaviour as a weakness or as a reaction to trauma. He preferred to be in trouble for reactions he couldn't control than to disclose his trauma or traumatic-stress reactions. He frequently used language such as, "I didn't want a pity party from anybody," and "I didn't want people to be 'oh so sorry about your past ... here's a cupcake,' I didn't want that." This attitude allowed Nick to present a tough exterior and deflect attention away from his trauma.

Although Nick found school to be confining, and he attended more to avoid home and to see friends than for academic purposes, there were aspects of school that were positive for him. He saw school as the only place where he could voice opinions, disagree, and speak his mind. Art class was also a very positive aspect of school for Nick, and an area where he excelled. He described how art and short stories gave him not only an outlet for self-expression but also relief from the flashbacks and intrusive memories. He recalled, "Those kind of classes were the classes where I absolutely felt free, my mind was clearest." Another positive for Nick was the presence of the "smoke hole" at school, which he described as "the only place in school where I felt safe." Although they did not discuss their situations, Nick says that other students at the smoke hole were "people that 
were in the same boat where very odd stuff had happened" and "we all kind of in a very silent way, kind of connected."

The majority of connections Nick had made with adults outside of school had taught him that adults could not be trusted and that respecting a person simply because they held a position of authority led to being hurt. Nick identified "seeing the few teachers that I liked and being able to go like 'hey what's up?'... you know and hear them saying 'hey Nick'," as one of the reasons why he looked forward to going to school. While exchanging a simple greeting may not seem very significant, it was these small gestures that identified to Nick that a teacher cared. Although Nick adamantly stated throughout that he did not want anyone to know about the trauma he had been through, he also said, "I never felt like I actually found anybody that I could talk to ... but I think if I would have, then I would have done a lot better."

He thought teachers perceived him as "just another drop in the pool, another one of the kids." Being middle class was part of the reason that Nick felt there was little opportunity for support. He assumed that teachers thought middle-class students "should be able to deal with issues on our own or just nobody cared or there wasn't a system in place." He felt that if a teacher had approached him and asked him if there was a reason why he was "smoking that much pot and being that kind of grumpy," then he would have told them his thoughts. Nick's impression of support at school was that "essentially everything we did we were left to fend for ourselves," and he recalled, "For a long time I felt kind of abandoned by it."

His advice for teachers centered on earning his respect and on seeing him "not as a student but as an individual." He wanted teachers to meet students "on our level," which to him meant turning "a blind eye to the things that really don't matter, like smoking, like swearing." Based on Nick's experiences, he truly believed that "the majority of kids like me, we just can't talk to anybody," and "the only way you are ever going to help somebody is if you find a way to connect with them on their level." As he expanded on this idea, it became clear that this connection for him was not necessarily to pave the path to disclosure, but rather to help him feel safer in class. He stated that having that connection was "the only time I felt I really ever could give the teachers the time of day, not to let them into my world, but to focus on what we were doing."

Summary. Nick's descriptions of his traumatic stress included behavioural overreactions, dissociation, and hypervigilence-all signs indicative of post-traumatic stress disorder (American Psychiatric Association, 2000). His externalized behaviour was sufficient to get him into trouble, but not sufficient to get him help or services. Nick described the trauma as ending at about age 16, and shortly thereafter, he was able to take control and make decisions to improve his well-being and functioning. This speaks to the dynamic nature of resilience; when the stressors were removed, he was able to access underlying strengths and capabilities. While Nick stayed in school, his perception of himself as an underachiever and his lack of engagement at school interfered with his ability to meet his full potential. 


\section{Cross-Case Analysis}

Despite very different traumatic events, school experiences, and outcomes, there were many similarities in Nick's, Natasha's, and Sarah's stories. Important to note is that all described how they could not have participated in this interview while in high school, and all spoke of how difficult it is to make sense of trauma while you are in it. The focus at that time was on survival and getting through the day. Sarah survived by separating herself from the trauma, Nick through drug use, and Natasha by ultimately deciding she needed to be away from school to manage her distress and to get through the day. Time and geographical distance from the trauma occurred after leaving school and were perceived by all three as being the factors that allowed them to deal with their issues and make meaning of their traumatic experiences.

\section{Bringing Traumatic Stress to School}

While all the main symptoms of traumatic stress (re-experiencing, avoidance, and hyperarousal) were evident in all cases to varying degrees, participants were more likely to refer to their stress as anxiety or "always being on edge." They were all aware to some extent that the traumatic stress was affecting their learning and functioning; however, the impact that the traumatic stress had on their well-being was seen as a greater issue than the impact on their learning in the classroom. When reflecting, both Nick and Natasha articulated ways in which they believed that their traumatic stress had a direct effect on their academic achievement and learning. Sarah was adamant that the trauma would not interfere with her academic success and managed to succeed despite the anxiety and stress she experienced. Efforts to decrease this anxiety were also a shared experience with all, primarily using "flight" through mental avoidance (dissociation) and physical avoidance (leaving class) to deal with the stress arousal response.

Control. In order for the participants to feel safe, and to diminish the stress arousal response, each of the participants sought out areas where they could assert a degree of control. Sarah saw academic achievement and maintaining high grades as being an area she could control. For Nick, standing his ground in dealing with those in authority and choosing who he would respect gave him a measure of control. Natasha struggled to find a way to control her distress or to overcome her sense of hopelessness that she could be successful at school, and ultimately her control came from leaving the school setting. A second area where participants took charge was in the choice to disclose or not to disclose their trauma to school officials. For Nick, keeping this information to himself was very important, as he believed that once people were aware, their perceptions of him would change. Sarah's choice not to disclose came from her belief that she knew best what she needed and that disclosure would interfere with her plans. For Natasha, the lack of response to her limited disclosure furthered her feelings of helplessness and loss of control, as disclosure did not lead to accessing needed support.

Depression and Substance Use. Mental health needs beyond post-traumatic stress are common in youth who have lived through trauma, and were evident here. At various points throughout their adolescence Natasha, Sarah, and Nick all struggled with depression and a sense of hopelessness. Participants also reported using disordered eating 
and self-harm as ways of coping with their depression. Sarah recounted becoming more and more withdrawn and quiet at school, making her efforts to connect or to seek help even more challenging. In all cases the depression magnified the challenges of the traumatic stress and contributed to some of the difficulties that the students experienced. Substance use was also a recurring theme. Nick began using drugs at an early age as a socially acceptable way to obtain relief from the emotional distress he felt, and when faced with a situation at school that made him feel threatened or unsafe, he would leave and get high. Similarly, for Sarah, drugs and alcohol provided relief from the symptoms and numbed the emotional pain. Natasha also used drugs frequently; however, she reported that drug use allowed her to express her pain and feel something, rather than cover it. Nick and Natasha spoke of their understanding of how their daily drug use contributed to the haze they were in during high school. All three participants spoke of an awareness of the negative effects that the drug and alcohol use were having on their lives by the end of high school and how it could complicate or prevent them from reaching future goals. (At the time of the interviews, one participant had stopped all use of drugs and alcohol, and the other two reported only occasional use.)

\section{Role of Peers}

As is typical in adolescence, peers played a key role in the participants' lives at school. Natasha, Sarah, and Nick all described seeking peers who could understand their pain and distress and spoke about seeing their peers as one of the main reasons for attending school. There seemed to be an unspoken bond among certain groups of peers that did not require the disclosure of details of the trauma to fit in. Natasha and Sarah both changed peer groups, feeling that their more socially conservative and high-achieving peers could no longer understand or relate to them. In all cases this shift in peer groups led to greater involvement in risk-taking behaviour and, in Nick's and Natasha's cases, to delinquency. While peers played a positive role in providing connection and support, they were detrimental to their overall well-being and to their academic engagement.

\section{Need for Connection and Caring Relationships}

The theme that stood out the most across all cases was the unmet need to establish caring connections with teachers at school. "Alone," "abandoned," "ignored," and "invisible" were words used to describe how Natasha, Sarah, and Nick felt during their high school years.

Teacher-Initiated Support. In looking at support available within the classroom, the participants all identified supportive teachers who they believed were caring individuals; yet they were unable to connect with these people in a way that might have contributed to an increased sense of support at school. The participants recalled being at a loss as to how to establish a relationship or begin to connect with these teachers, and they wanted teachers to reach out and take that first step. The need to build trust was a key aspect and one that, as both Nick and Sarah emphasized, required time. They acknowledged the workload that teachers have and the limited opportunities to develop student-teacher relationships that extend beyond academics as part of the issue. When pressed for what they wanted from these connections, it was evident that the offer of 
support and the knowledge that a supportive, caring person was reaching out and available was more important than the specifics of the support itself.

Demonstration of caring behaviour. Interestingly, although not surprisingly, based on previous research, it was the small things that mattered to the students and that demonstrated caring behaviour. Natasha spoke of teachers smiling or offering her food. Nick recalled teachers saying "hi" in the mornings and using his name in greeting as being a highlight for him. All spoke of the need for their distress to be noticed and validated by teachers, and of the need for understanding. The youth spoke of wanting teachers to ask them if they were okay and if they needed anything. In the end it was the demonstration of caring behaviour in the form of validation, flexibility, understanding, and empathy that the youth looked for to meet their needs.

Relate to the person. Each of the participants also spoke of the need for teachers to relate to them on a "different" level, beyond that of an academic learner. They described this as getting to know them as a "person, not a student," as "a human" and as "a friend." Nick described teachers needing to look past behaviours such as smoking or swearing in order to connect with the person behind the behaviour. Sarah felt that teachers saw her only as a strong student, and did not look beyond that to see who she was as a social, emotional person.

\section{Role of School}

School served a significant purpose for each participant. Sarah and Nick spoke of school playing an important role in getting them away from home. In Sarah's case, school and being academically successful was what allowed her to have hope and to remain future oriented. Seeing teachers who cared was also seen as a common reason for wanting to attend school, and all of the young adults spoke of at least one adult in the school setting who provided support to them. Even for Natasha, talking with supportive school staff was a bright spot in her school day.

All participants, but particularly Nick and Sarah, spoke about the benefits that art and creative writing provided for self-expression and stress management. For Nick, art class was related to safety and a reduction in flashbacks and stress arousal. Sarah found great comfort in being able to express herself through stories and art, both of which were cathartic for her. Natasha spoke of her favourite part of school as being design class and showed the researcher a number of collages and pieces of art she had created that expressed her distress. While Natasha did not specifically see art as being school-based she shared the positive outlook on art and writing that Nick and Sarah commented on.

\section{Summary}

Each participant had a unique story with differing experiences of trauma, yet common threads stood out clearly across all three cases. The negative impact of the trauma on their mental health and well-being was undeniable. Frustration and confusion with finding help while in high school was apparent across the case studies. Their collective need for connected relationships with teachers they perceived as caring and respectful was paramount. What the young adults wanted from teachers was not a 
therapist or any immediate intervention, but rather someone who would notice them, validate their distress, reach out to them, care about them as people, and look out for their overall well-being. The patterns that emerged from this cross-case analysis solidify the need for enhanced teacher awareness and responsiveness to youth in similar circumstances.

\section{Discussion}

The educational experience of each youth was unique, with school being a negative experience for Natasha, a positive experience for Sarah, and an indifferent experience for Nick. Despite these differing attitudes toward school, the impact of the trauma on their lives was apparent and shared across cases (Perry, 2002; Steele, 2002). Nick and Natasha spoke explicitly about the difficulties they perceived the traumatic stress reactions (fightflight-freeze) created for them at school, and the difficulties the stress caused for their learning and academic achievement. Academic disengagement and lowered achievement are well documented in the literature as outcomes of trauma (Beers \& DeBellis, 2002; Horsman, 2004; Slade \& Wissow, 2007). All three managed their distress at school by leaving class and making efforts to avoid people, places, and situations that were anxiety provoking. Avoidance, while a common coping strategy for anxiety, is problematic in the school setting where being present is essential to learning.

The unique way in which each youth displayed and managed their traumatic stress means that educators must be attuned to many possible signs of student distress. As the distress is filtered through personality, coping mechanisms, personal meaning, and internal capabilities, there is no one common presentation in the context of the classroom (Cook et al., 2005; Perry, 2002; Saakvitne et al., 1998). The three participants used common coping strategies, including externalizing and internalizing behaviours (Perry, 2002) and self-destructive or delinquent behaviour (Bardone et al., 1998; Edwards et al., 2004; Woodward \& Fergusson, 2005). Another way of coping that came through strongly in this research were more subtle displays: changes in clothing, peer groups, and lifestyle choices that the participants reported as a way of showing their distress. Distinguishing between changes that represent distress and those that represent typical teenage exploration is challenging. The participants suggested the importance of asking students about changes in their peers and lifestyle, rather than making a default assumption that they were exploring their identity.

Returning to the theoretical framework that was presented earlier in the paper, the unmet needs and diminished sense of agency described in the constructivist selfdevelopment theory (McCann \& Pearlman, 1992) were evident in the participants' stories. The foundational areas of need that CSDT poses as being most affected by trauma (safety, self-esteem, trust, intimacy, and control) were apparent to varying degrees in each of the youth. Nick and Natasha both describe feelings of being on edge or having their guard up while at school, and neither saw school as a place where they could relax or feel safe. In Sarah's case, school was her safe place, which may explain why she experienced fewer symptoms at school, and why her stress had less effect on her learning. Nick spoke of developing disordered eating habits to deal with low self-esteem, and two of the young adults admitted to self-harming, to suicidal thoughts and to struggling with self-worth. All three spoke of wanting to trust but were unsure of how to begin to 
establish a trusting relationship. In Nick's case, he was very hesitant to trust teachers or to respect their authority, and he described that importance of seeing trust as a process that takes time to develop.

The desire to have intimacy and connect with self and others was present for all three participants. Sarah recounted frequent reinventions of herself-from goth to punk to Buddhism in an effort to connect with her own emotions and also with others who shared her emotions. Natasha's reason for leaving school was a feeling of disconnection from people, a known cause of early school leaving (Ferguson et al., 2005). Each of the youth spoke of a desire to connect with teachers and of their feelings of inadequacy in trying to initiate those connections. They also spoke of connections they did have, although they were not ones they could draw on while in the classroom. Natasha found support staff individuals at school with whom she did connect, and Nick reported a strong relationship with his grandmother, while Sarah spoke of receiving support from her boss at work. Lastly, control was a theme throughout. Nick spoke of his feeling of being out of control of his physical reactions at times when responding to triggers. Natasha avoided class due to fear of losing control of her emotions. Sarah was the only participant who was able to stay in control through great effort and sacrifice, including living a double life and putting on a mask.

Each of these unmet needs is an area that teachers and school personnel can address in the school context. In their advice for teachers, the participants touched on each of the elements in the RICH relationships framework (Saakvitne, Gamble, Pearlman, \& Lev, 2000) that are part of trauma-informed practices. They wanted respect, more information, to connect, and to be given hope (knowing they weren't alone, knowing that they mattered) in the school context. Schools and classrooms can be safe environments where trusting relationships can be formed with educators and where connections ca be built among student, teachers, and peers. Mutual respect, validation, and provision of resources are not time intensive and are efforts that the participants perceived as being supportive. Relationships fit well within the framework of school connectedness and offer opportunities to build self-worth and feel a sense of control over self and environment.

\section{School Connectedness}

For students to be able to learn in the classroom there has to be a sense of safety and an ability to manage feelings, and it is in these areas that teachers can provide support (Blum, 2005; Mihalas, Morse, Allsopp, \& McHatton, 2009). Support does not need to take the form of conversations on trauma in order to be trauma sensitive. A supportive adult can walk students through the process of advocating for services and encourage them in seeking services that meet their needs (Jaffee \& Gallop, 2007; Masten \& MottiStefanidi, 2009). As seen from the work of Walter et al. (2006), for many students, teachers are the only professional adults in their lives who might be able to take on this role; and this was true for Nick and Sarah. For students with trauma, the lack of trust in adults and the uncertainty of how someone will respond to their needs is a barrier to seeking help (Cook et al., 2005). Engagement at school is important to youths' ability to seek help and find adults who can refer or offer resources or support. 
The need for relational engagement at school remains a core need across demographics. While many of the typical risk characteristics (i.e., poverty, early academic failure, single-parent homes) were not present in the three cases here, the paramount need they had for a caring, supportive connection to an adult was strong. Similar to the findings of Ozer et al. (2008), Natasha, Nick, and Sarah stated that it was feeling a sense of belonging and being noticed that led to increased engagement with school and to a greater sense of well-being. All felt that being able to slip out of class or to have an emotional outburst go unnoticed indicated a lack of care or concern for their well-being.

Typical strategies for supporting the mental health and well-being of students include teaching adaptively, providing accommodations, and making referrals for mental health assessments and services when necessary (Dods, Hutchinson, \& Dalton, 2009). Along with these, a shift in professional identity is needed. Mihalas et al. (2009) contended that in order to feel empowered in the classroom, educators need to see themselves not just as teachers but as professionals whose role includes emotional and social education as well as academic instruction. In addition, they must have a goal of overall student well-being and success. They discussed practices that teachers can implement at the individual level to build caring relationships: (a) be a student advocate; (b) get to know students and their lives; (c) invite students to be partners in their education; (d) actively listen; and (e) celebrate success. These actions and the subsequent outcome of engagement, as well as the development of a student-teacher relationship, are critical to success for struggling students.

\section{Conclusion}

Despite teachers' misgivings that they do not have sufficient knowledge or that they are not the best person to help, the findings here reinforce that teachers can meet the needs of students similar to Natasha, Nick, and Sarah. What the students wanted from teachers was a strong, supportive connection. Building a caring relationship with students is a much more manageable task for teachers then dealing with student mental health. Some students may use that relationship to share issues and feelings that require more specialized clinical services, and the teacher can then become the vehicle through which the students can access needed resources. This relationship can also provide an ally to advocate for or support the student in reaching out for help or in procuring services for students who do not reach out on their own. The emphasis from the participants was that it was the impact on their overall well-being that caused them distress and difficulty, rather than any particular clinical symptom. Traumatic stress symptoms were present but were acknowledged as an accepted part of life, and it was the altered perceptions of the world around them, the lack of a connection with a supportive adult, the sense of being alone, and the depression that diminished their overall well-being.

According to resilience research (Luthar, Ciccetti, \& Becker, 2000), a focus on risk or resilience that is based solely on functioning, either academic or social, can mean that strong academic students whose well-being and emotional health are tenuous can be overlooked. A finding that high-achieving students typically maintain academic functioning despite dealing with considerable adversity (Carney, 2008) was true for Sarah. This study also highlights the importance of widening the view of at-risk students, 
as the participants here did not have typical social or academic characteristics of risk but were in need of similar supports.

A limitation of this study is that these three young adults are not representative of all youth who have experienced trauma. The screening criteria also limited the study to inclusion of articulate youth with stable mental health and well-established support systems. As with any retrospective study, a further limitation is recall bias. Efforts to minimize such bias included recruiting participants who had been out of high school for less than three years and focusing the interview on the meaning each participant made of their experience rather than on details of specific traumatic events. All participants provided first-person reports and were able to articulate their experiences without difficulty.

Ultimately the issue remains that there is a disconnect. Students need caring supportive adults in their lives at school, and teachers are available and willing to fill this role, yet for many this bridge is hard to construct. The contrasting stories told here speak to the individual nature of the education experience of youth who have a history of trauma, and the challenge that range of individual experiences presents for educators. The shared aspects of the stories contribute to our understanding of the role of relational engagement and are relevant to teaching practice. Greater initiative from teachers in approaching students who are struggling is essential; however, first increased professional learning about mental health is needed for teachers to ensure they are comfortable supporting and advocating for these needs. In the interim, building relationships is an avenue for meeting needs. Hearing directly from the youth in this research has informed an understanding of the trauma-related challenges they faced throughout high school, and the important role that teachers and schools played in supporting their well-being and future outcomes. Deepening our understanding of the role of school connectedness in meeting mental health needs is an important area for future research. These findings highlight the importance of focusing research on student wellbeing and on the development of teaching and school practices that support student mental health.

\section{References}

American Psychiatric Association. 2000). Diagnostic and statistical manual of mental disorders. (4th ed., text rev.). Washington, DC: Author.

Arroyo, W. (2001). PTSD in children and adolescents in the juvenile justice system. In S. Eth (Ed.). Review of psychiatry, vol. 20, PTSD in children and adolescents (1st ed.), pp. 59-86.

Bardone, A., Moffitt, T. E., Caspi, A., Dickson, N., Stanton, W. R., \& Silva, P. A. (1998). Adult physical health outcomes of adolescent girls with conduct disorder, depression, and anxiety. Journal of the American Academy of Child and Adolescent Psychiatry, 37(6), 594-602.

Beers, S. R., \& De Bellis, M. D. (2002). Neuropsychological function in children with maltreatmentrelated posttraumatic stress disorder. American Journal of Psychiatry, 159(3), 483-486.

Blum, R. (2005) A case for school connectedness. Educational Leadership, 62(7), 16-20.

Bond, L., Butler, H., Thomas, L., Carlin, J., Glover, S., Bowes, G., \& Patton, G. (2007). Social and school connectedness in early secondary school as predictors of late teenage substance use, mental health, and academic outcomes. Journal of Adolescent Health, 40(4), 9-18. 
Briere, J., Elliott, D. M., Harris, K., \& Cotman, A. (1995). Trauma Symptom Inventory: Psychometrics and association with childhood and adult trauma in clinical samples. Journal of Interpersonal Violence, 10, 387-401.

Calabrese, R., Hummel, C., \& San Martin, T. (2007). Learning to appreciate at-risk students. International Journal of Educational Management, 21(4), 275-291.

Carney, J. V. (2008). Perceptions of bullying and associated trauma during adolescence. Professional School Counseling, 11(3), 179-188.

Cole, M., \& Styron, R. A. (2006). Traditional or online methods of professional development: What do teachers prefer? Journal of Research for Educational Leaders, 3(2), 24-38.

Cook, A., Spinazzola, P., Ford, J., Lanktree, C., Blaustein, M., Cloitre, M., ...van der Kolk, B. (2005). Complex trauma in children and adolescents. Psychiatric Annals, 35(5), 390-398.

Copeland, W. E., Keeler, G., Angold, A., \& Costello, E. J. (2007). Traumatic events and posttraumatic stress in childhood. Archives of General Psychiatry, 64(5), 577-584

Costello, J., Erkanli, A., Fairbank, J., \& Angold, A. (2002). The prevalence of potentially traumatic events in childhood and adolescence. Journal of Traumatic Stress, 15(2), 99-112.

De Bellis, M. (2005). Developmental traumatology: Neurobiological development of maltreated children with PTSD. Australian and New Zealand Journal of Psychiatry, 39, A108-A108.

Dods, J., Hutchinson, N., \& Dalton, CJ. (2009, May). Supporting the mental health needs of students in high school. Prepared for MISA-East PNC. Toronto, ON: Ontario Ministry of Education.

Downey, L. (2007). Calmer classrooms: A guide to working with traumatised children. Child Safety Commissioner, Melbourne, Australia. Retrieved on February 12, 2008 from http://www.ocsc.vic.gov.au/downloads/calmer_classrooms.pdfDuncan, R. (2000). Childhood Maltreatment and College Drop-Out Rates. Journal of Interpersonal Violence, 15(9), 987-995.

Dwyer, S. B., Nicholson, J. M., Battistutta, D., \& Oldenburg, B. (2005). Teachers' knowledge of children's exposure to family risk factors: Accuracy and usefulness. Journal of School Psychology, 43(1), 23-38.

Edwards, V. J., Anda, R. F., Dube, S. R., Dong, M., Chapman, D. F., \& Felitti, V. J. (2005). The wideranging health consequences of adverse childhood experiences. In K. Kendall-Tackett \& S. Giacomoni (Eds.). Victimization of children and youth: Patterns of abuse, response strategies. Kingston, NJ: Civic Research Institute.

Edwards, V. J., Anda, R. F., Felitti, V. J., \& Dube, S. R. (2004). Adverse childhood experiences and health-related quality of life as an adult. Washington: American Psychological Association.

Ferguson, B., Tilleczek, K., Boydell, K., Rummens, J. A., Cote, D., \& Roth-Edney, D. (2005). Early school leavers: Understanding the lived reality of student disengagement from secondary school. Final Report submitted to the Ontario Ministry of Education, May 31, 2005.

Funk, R., McDermeit, M., Godley, S., \& Adams, L. (2003). Maltreatment issues by level of adolescent substance abuse treatment: The extent of the problem at intake and relationship to early outcomes. Child Maltreatment, 8(1), 36-45.

Hall, W., Degenhardt, L., \& Teesson, M. (2009). Understanding comorbidity between substance use, anxiety and affective disorders: Broadening the research base. Addictive Behaviors, 34(6-7), 526-530.Horseman, J. (2004). The challenge to create a safer learning environment for youth. Parkdale Project Read. Spiral Community Resource Group.

Hutchinson, N. (2009). Inclusion of exceptional learners in Canadian classrooms: A practical handbook for teachers. Toronto, ON: Pearson Canada. 
Jaffee, S. R., \& Gallop, R. (2007). Social, emotional, and academic competence among children who have had contact with child protective services: Prevalence and stability estimates. Journal of the American Academy of Child \& Adolescent Psychiatry, 46(6), 757-765.

Johnson, W., McGue, M., \& Iacono, W. G. (2006). Genetic and environmental influences on academic achievement trajectories during adolescence. Developmental Psychology, 42(3), 514-531.

Kendall-Tackett, K. A., \& Eckenrode, J. (1997). The effects of neglect on academic achievement and disciplinary problems: A developmental perspective. Thousand Oaks, CA: Sage Publications.

Klem, A., \& Connell, J. (2004). Relationships matter: Linking teacher support to student engagement and achievement. Journal of School Health, 74(7), 262-273.

Liamputtong, P., \& Ezzy, D. (2005). Qualitative research methods (2nd ed.). Melbourne, Austrialia: Oxford University Press.

Lipschitz, D. S., Winegar, R. K., Hartnick, E., Foote, B., \& Southwick, S. M. (1999). Posttraumatic stress disorder in hospitalized adolescents: Psychiatric comorbidity and clinical correlates. Journal of the American Academy of Child and Adolescent Psychiatry, 38, 385-392.

Luthar, S., Cicchetti, D., \& Becker, B. (2000). The construct of resilience: A critical evaluation and guidelines for future work. Child Development, 71(3), 543-562.

Mansour, M. E., Kotagal, U. P., DeWitt, T. G., Rose, B., \& Sherman, S. N. (2002). Urban elementary school personnel's perceptions of student health and student health needs. Ambulatory Pediatrics, 2(2), 127-131.

Masten, A. S., \& Motti-Stefanidi, F. (2009). Understanding and promoting resilience in children: Promotive and protective processes in schools. In T. B. Gutkin \& C. R. Reynolds (Eds.), The handbook of school psychology (4th ed.). (pp. 721-738). New York, NY: Wiley.

McCann, I., \& Pearlman, L. (1992). Constructivist self-development theory: A theoretical framework for assessing and treating traumatized college students. Journal of the American College of Health, 40(4), 189-196.

McNeeley, C. (2005). Connection to school. In K. A. Moore \& L. H. Lippman (Eds.), What do children need to flourish: Conceptualizing and measuring indicators of positive development (pp. 289-303). New York:Springer

McNeeley, C., Nonnemaker, J., \& Blum, R. (2002). Promoting school connectedness: Evidence from the National Longitudinal Study of Adolescent Health. Journal of School Health, 72(4), 138-146.

Meichenbaum, D. (2006). How educators can nurture resilience in high-risk children and their families. Retrieved on May 10, 2008 from www.teachsafeschools.org/Resilience.pdf

Mihalas, S., Morse, W. C., Allsopp, D. H., \& McHatton, P. A. (2009). Cultivating caring relationships between teachers and secondary students with emotional and behavioral disorders: Implications for research and practice. Remedial and Special Education, 30(2), 108-125.

Ozer, E., Wolf, J., \& Kong, C. (2008). Sources of perceived school connectedness among ethnically diverse urban adolescents. Journal of Adolescent Research, 22(4), 438-470.

Patton, M. (2002). Qualitative research and evaluation methods. Thousand Oaks, California: Sage Publications.

Pearlman, L. A. (2013). Restoring self in community: Collective approaches to psychological trauma after genocide. Journal of Social Issues, 69(1), 111-124.

Perry, B. D. (2002). Childhood experience and the expression of genetic potential: What childhood neglect tells us about nature and nurture. Brain and Mind: A Transdisciplinary Journal of Neuroscience and Neurophilosophy, 3(2), 79-100. 
Ratner, H. H., Chiodo, L., Covington, C., Sokol, R. J., Ager, J., \& Delaney-Black, V. (2006). Violence exposure, IQ, academic performance, and children's perception of safety: Evidence of protective effects. Merrill-Palmer Quarterly, 52(2), 264-287.

Rowe, E., \& Eckenrode, J. (1999). The timing of academic difficulties among maltreated and nonmaltreated children. Child Abuse \& Neglect, 23(8), 813-832.

Saakvitne, K. W., Gamble, S., Pearlman, L. A., \& Lev, B. (2000). Risking connection: A training curriculum for working with survivors of childhood abuse. Lutherville, MD: Sidron Press.

Saakvitne, K. W., Tennen, H., \& Affleck, G. (1998). Exploring thriving in the context of clinical trauma theory: Constructivist self development theory. Journal of Social Issues (special issue), Thriving: Broadening the Paradigm Beyond Illness to Health, 54(2), 279-299.

Saewyc, E., Wang, N., Chittenden, M., Murphy, A., \& The McCreary Centre Society (2006). Building Resilience in Vulnerable Youth. Vancouver, BC: The McCreary Centre Society.

Slade, E. P., \& Wissow, L. S. (2007). The influence of childhood maltreatment on adolescents' academic performance. Economics of Educational Review, 26(5), 604-614.

Sullivan, P. M., \& Knutson, J. F. (2000). Maltreatment and disabilities: A population-based epidemiological study. Child Abuse and Neglect, 24(10), 1257-1273.

Stake, R. Qualitative case studies. In N. K. Denzin \& Y. S. Lincoln (Eds.), The Sage handbook of qualitative research, 3rd ed. (pp. 443-466). Thousand Oaks, CA: Sage Publications.

Steele, W. (2002). Trauma's impact on learning and behavior: A case for intervention in schools. Trauma and Loss: Research and Interventions, 2(2), 34-47.

Terr, L. C. (1991). Childhood traumas: An outline and overview. American Journal of Psychiatry, 148(1), 10-20.

Vida, R., Brownlie, E. B., Beitchman, J. H., Adlaf, E. M., Atkinson, L., Escobar, M... Bender, D.(2009). Emerging adult outcomes of adolescent psychiatric and substance use disorders. Addictive Behaviors, 34(10), 800-805.

Walter, H. J., Gouze, K., \& Lim, K. G. (2006). Teachers' beliefs about mental health needs in inner city elementary schools. Journal of the American Academy of Child \& Adolescent Psychiatry, 45(1), 61-68.

Wilson, D., \& Elliott, D. (2003, June). The interface of school climate and school connectedness: An exploratory review and study. Paper presented at the Winspread Conference on School Connectedness: Strengthening Health and Educational Outcomes for Teens, Racine, Wisconsin.

Woodward L. J., Fergusson D. M. (2005). Life course outcomes of young people with anxiety disorders in adolescence. Journal of the American Academy of Child and Adolescent Psychiatry, 40(9), 1086-1093.

Yasik, A. E., Saigh, P. A., Oberfield, R. A., \& Halamandaris, P. V. (2007). Posttraumatic stress disorder: Memory and learning performance in children and adolescents. Biological Psychiatry, 61(3), 382-388.

Yule, W. (2001). Post-traumatic stress disorder in children and adolescents. Internal Review of Psychiatry, 13(3), 194-200.

\section{Author's Note}

Correspondence concerning this article should be addressed to Jennifer Dods, Faculty of Education, 511 Union St, Queen's University, Kingston, ON, K7M 5R7, Canada. Email: jennifer.dods@queensu.ca 